\title{
Comparing model performance of two rainfall-runoff models in the Rhine basin using different atmospheric forcing data sets
}

\author{
A. H. te Linde ${ }^{1,2}$, J. C. J. H. Aerts ${ }^{1}$, R. T. W. L. Hurkmans ${ }^{3}$, and M. Eberle ${ }^{4}$ \\ ${ }^{1}$ Institute for Environmental Studies (IVM), Faculty of Earth and Life Sciences, Vrije Universiteit, De Boelelaan 1087, 1081 \\ HV Amsterdam, The Netherlands \\ ${ }^{2}$ Deltares, Rotterdamseweg 185, 2629 HD Delft, The Netherlands \\ ${ }^{3}$ Hydrology and Quantitative Water Management, Wageningen University, Droevendaalsesteeg 4, \\ 6708 PB Wageningen, The Netherlands \\ ${ }^{4}$ Federal Institute of Hydrology (BfG), Am Mainzer Tor 1, D-56068 Koblenz, Germany
}

Received: 16 November 2007 - Published in Hydrol. Earth Syst. Sci. Discuss.: 4 December 2007

Revised: 19 March 2008 - Accepted: 22 May 2008 - Published: 25 June 2008

\begin{abstract}
Due to the growing wish and necessity to simulate the possible effects of climate change on the discharge regime on large rivers such as the Rhine in Europe, there is a need for well performing hydrological models that can be applied in climate change scenario studies. There exists large variety in available models and there is an ongoing debate in research on rainfall-runoff modelling on whether or not physically based distributed models better represent observed discharges than conceptual lumped model approaches do. In addition, it is argued that Land Surface Models (LSMs) carry the potential to accurately estimate hydrological partitioning, because they solve the coupled water and energy balance. In this paper, the hydrological models HBV and VIC were compared for the Rhine basin by testing their performance in simulating discharge. Overall, the semi-distributed conceptual HBV model performed much better than the distributed land surface model VIC ( $E=0.62, r^{2}=0.65$ vs. $E=0.31, r^{2}=0.54$ at Lobith). It is argued here that even for a well-documented river basin such as the Rhine, more complex modelling does not automatically lead to better results. Moreover, it is concluded that meteorological forcing data has a considerable influence on model performance, irrespectively to the type of model structure and the need for ground-based meteorological measurements is emphasized.
\end{abstract}

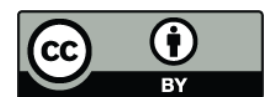

Correspondence to: A. H. te Linde (aline.te.linde@ivm.vu.nl)

\section{Introduction}

It is expected that climate change will have major implications for the discharge regime of many rivers around the world (Kundzewicz et al., 2007). Changes in seasonal discharge are projected for river basins in mid-latitude regions, such as the Rhine basin in Europe. Seasonal discharge will most likely shift to more discharge in winter and less discharge in summer, and the frequencies of floods and droughts are expected to increase (Buishand and Lenderink, 2004; Kwadijk, 1993; Middelkoop et al., 2001). Recent climate change research focuses on simulating changes in the magnitude and frequencies of flood events using different models that are either developed for scenario studies, real time flood forecasting, or both (Van Deursen, 2006; Te Linde, 2007). Our understanding of the discharge generating processes in the Rhine basin, though, is still deficient and modelling results for describing the current hydrological situation at basin scale are of moderate quality. For instance, extreme events inside the calibrated range are both over and underestimated and it is difficult to separate the effects of errors in input data and model structure (Weerts, 2003). This increases the inherent uncertainty when using models outside their calibrated range, as is common practice in climate scenarios studies. Thus there is a need for a well performing hydrological model on extreme events that can be applied in various climate scenario studies, but there exists large variety in available models. Since these issues are common in applications of hydrological modelling in other regions as well, we chose to compare two rainfall-runoff models for the Rhine basin with divergent model structures.

Published by Copernicus Publications on behalf of the European Geosciences Union. 
The semi-distributed conceptual model HBV (Hydrologiska Byråns Vattenbalansavdelning) (Bergström, 1976; Lindström et al., 1997) has been applied in multiple studies for the Rhine basin since 1999 by both the German Federal Institute of Hydrology and the Dutch Ministry of Transport, Public Works and Water Management (Mülders et al., 1999; Weerts and Van der Klis, 2004; Eberle et al., 2005). However, the HBV model does not exactly describe all the physical processes that are believed to be of major importance for the simulation of timing and magnitude of extreme flood and drought events (Schär, 1998; Ward and Robinson, 2000). Potential evaporation, for example, is calculated using the Penman-Wendling approach based on temperature and sunshine duration (Eberle et al., 2005) while more innovative methods are available using coupled water and energy balance simulations. Recently the state of the art distributed land surface model (LSM) VIC (Variable Infiltration Capacity) (Liang et al., 1994) has been applied on the Rhine basin (Hurkmans et al., 2008), which does describe all relevant land surface processes, including the energy balance, and therefore carries the potential to estimate hydrological partitioning more accurately than the HBV model does. Because of a realistic representation of evaporation processes in land surface models such as done within VIC, Troy et al. (2007) argue that these types of models are inevitable when performing climate and land use change scenario studies.

However, the application of a distributed land surface model such as VIC at a macro-scale river basin, such as the Rhine basin, is still a highly simplified representation because of its spatial resolution. Even when using a very fine grid, in the order of tens or hundreds of meters and by that sabotaging calculation time, it will never represent actual processes that vary at a scale of trees and ditches (Uhlenbrook, 2003) and the actual heterogeneity of hydrological processes. Considering the required input data and computer capacity, the question remains whether more complex and demanding models such as VIC can be preferred over simpler, conceptual water balance models such as HBV. A better understanding of the use and capacity of different hydrological models would enhance the confidence in future climate scenario studies using these hydrological models. An uncertainty analysis of all processing steps from climate scenarios via downscaling methods to hydrological modelling is required. Estimating uncertainty of model simulations starts with analysing model performance using historical data. In this view, the goal of this paper is to compare the hydrological models HBV and VIC by testing their performance for simulating historical discharge. Based on the performance of both models, a recommendation can be made for the type of hydrological model to be preferred for climate change scenario studies.

Since both models have a different physical structure resulting from a different theoretical background, the divergent concepts in rainfall-runoff modelling are first addressed in Sect. 2. In Sect. 3, the models and study area are described.
In Sect. 4, the methods that are used for comparing atmospheric forcing data and model performance are explained, whereupon the results are presented in Sect. 5. Finally, the results are discussed and several conclusions are drawn in Sect. 6 .

\section{Divergent concepts in rainfall-runoff modelling}

There is an ongoing debate in research on rainfall-runoff modelling on the utility of more complex distributed models that aim to describe all physical processes, including soilatmosphere feedback processes. In the last decades the hydrologic community has devoted a great deal of attention to the understanding of hydrological processes and their representation by means of physically based, distributed models. The general idea of physically based, distributed modelling is that it represents reality better than lumped model approaches, as it takes into account spatial information and even more important, it uses physical law (mass balance and energy equations) to describe the hydrological processes (Refsgaard, 1996; Reggiani and Schellekens, 2003). However, it is well recognized that the available approaches are often still far from providing a satisfactory representation of rainfall-runoff transformation (Bergström et al., 2002). A lot of work remains in identifying different runoff response mechanisms and to characterize the key state variables during calibration (Perrin et al., 2000; Uhlenbrook et al., 1999; Wagener, 2003). This should be done by extensive and long duration field observations, using the growing availability of radar and space high-resolution datasets, improving physical descriptions and refining grid size. Examples of physically based, distributed models are SHE (Abbott et al., 1986), FLOWSIM (Rientjes and Zaadnoordijk, 2000), WASIM-ETH (Schulla and Kaspar, 2006), LARSIM (Ludwig and Bremicker, 2006), REW (Reggiani et al., 1998, 1999), LISFLOOD (De Roo et al., 1998, 2000), TOPKAPI (Liu and Todini, 2002) and tRIBS (Vivoni, 2003). Related to these models are land surface model (LSMs). The original purpose of LSMs was to represent the land surface in (regional) climate simulations used for climate models and numerical weather prediction (Liang et al., 1994). Recently, LSMs have been used for streamflow forecasting as well. By solving both the water and energy balance, LSMs are able to exploit a larger part of the information provided by regional climate model output (Hurkmans et al., 2008), which is an advantage in climate change scenario studies where regional climate model (RCM) output is used. But because of the complex model structure and the large number of parameters in LSMs, they are generally difficult to parameterize. Furthermore, in most of these distributed modelling approaches, it remains difficult to represent processes occurring at scales smaller than the grid or element scale. The VIC model therefore offers sub-grid scale variation in vegetation and soil characteristics (Liang et al., 1994). 
On the other hand, some researchers advocate a more straightforward hydrologic approach claiming that more complex modelling does not always lead to better results. Depending on dominant processes, data availability, scale and application of the model, one should select the appropriate modelling approach which can result in using a very simple model (Booij, 2003; Seibert, 1999). When formulating their famous and widely used performance criterion, Nash and Sutcliffe (1970) already warned for the risk of over-parameterized models. In recent years, the debate on model complexity versus model performance has intensified again and Beven (2001, 2002a, b) goes a step further and critically analyzed the constraints of distributed modelling. The perfect hydrological model that represents reality accurately will never exist, as there will always remain necessary approximations of processes and parameters at the model element scale. Beven (2001) claims that the ongoing pursue to a realistic representation has led to unjustified determinism in many distributed modelling applications and a lack of recognition of the problems of distributed modelling such as nonlinearity, scale and equifinality (which arises when many different parameter sets give equally good results). Furthermore, Savenije (2001) states that the large number of parameters in distributed models make it possible to represent hydrological behaviour well for the current situation, but due to over-parameterization these models are not the right tools to describe what will happen if certain characteristics of the basin change, such as land use or soil characteristics. Savenije (2001) suggests to further develop a new data-based top down approach (Jothityangkoon et al., 2001) in which relatively simple basin response functions describe complex hydrological processes at scales with sufficient level of aggregation. It consists of beginning with a large time step and gradually introducing the complexity required to meet the needs of shorter time steps. This resembles the conceptual approach of already long-existing water balance models like Sacramento, HBV and RhineFlow (Van Deursen and Kwadijk, 1993). Bogaard (2005) argues that the main challenges in understanding discharge generating processes appear to be related to the scale of the processes. Micro scale hydrological processes are highly heterogeneous, non-linear and interconnected, with the consequence that upscaling from micro- to basin scale and subsequent parameterization is practically impossible. In conclusion, hydrologists are looking for answers to match the observed complexity at the plot-scale, with the apparent simplicity that arises at the basin scale. Comparing the HBV and VIC models, having opposed model structures, for their performance in a welldocumented river basin like the Rhine basin, will add to the debate on divergent concepts in hydrological modelling.

\section{Model description and study area}

\subsection{VIC}

The Variable Infiltration Capacity (VIC) model (Liang and Zhenghui, 2001; Liang et al., 1994) is a distributed, macro-scale land surface model with a physically based soil-vegetation-atmosphere transfer scheme (SVATS), which solves both the water and energy balance. It is distinguished from other SVATS by its focus on runoff processes. These are represented through the variable infiltration curve, a parameterization of the effects of sub-grid variability in soil moisture holding capacity, from which the model takes its name, and a representation of non-linear baseflow. Routing of surface runoff and baseflow is done by the algorithm developed by Lohmann et al. (1996). A more extensive description of the modelling scheme is available in Hurkmans (2008), who recently developed the VIC model for the Rhine basin at a spatial resolution of $0.05 \times 0.05$ degree. The seven required atmospheric input time series are derived from a re-analysis dataset and are described in Sect. 4.1.

\subsection{HBV}

The HBV-96 model (Hydrologiska Byråns Vattenbalansavdelning) (Bergström, 1976; Lindström et al., 1997) model is a semi-distributed conceptual model. The model that is used in this study simulates discharge on a daily basis for 134 sub-basins of the Rhine. The model simulates snow accumulation, snowmelt, actual evapotranspiration, soil moisture storage, groundwater depth and runoff. The required forcing data are precipitation, temperature, and potential evaporation. The model consists of different routines in which snowmelt is computed by a day-degree relation, and groundwater recharge and actual evaporation are functions of actual water storage in a soil box. Discharge formation is represented by a linear reservoir for base flow and a non-linear approach for fast runoff components. The sub-basins are linked together with a simplified Muskingum approach (Shaw, 2002) to simulate routing processes. The HBV model was developed for the Rhine in several steps since 1997 by the Dutch Institute for Inland Water Management and Waste Water Treatment (RIZA) and the German Federal Institute of Hydrology (BfG). A complete description of the HBV calculation scheme and the model structure for the Rhine basin is found in Eberle et al. (2005).

\subsection{Rhine basin}

The study area includes the Rhine basin (Fig. 1) upstream of the Dutch-German border and covers an area of $160800 \mathrm{~km}^{2}$. The Rhine originates in the Alpine mountains that comprise almost $36000 \mathrm{~km}^{2}$ upstream of Basel, with maximum elevations of more than $4000 \mathrm{~m}$ a.s.l. Air temperatures are below zero during the winter season due to this height, and a substantial part of the precipitation is stored as snow. Land 

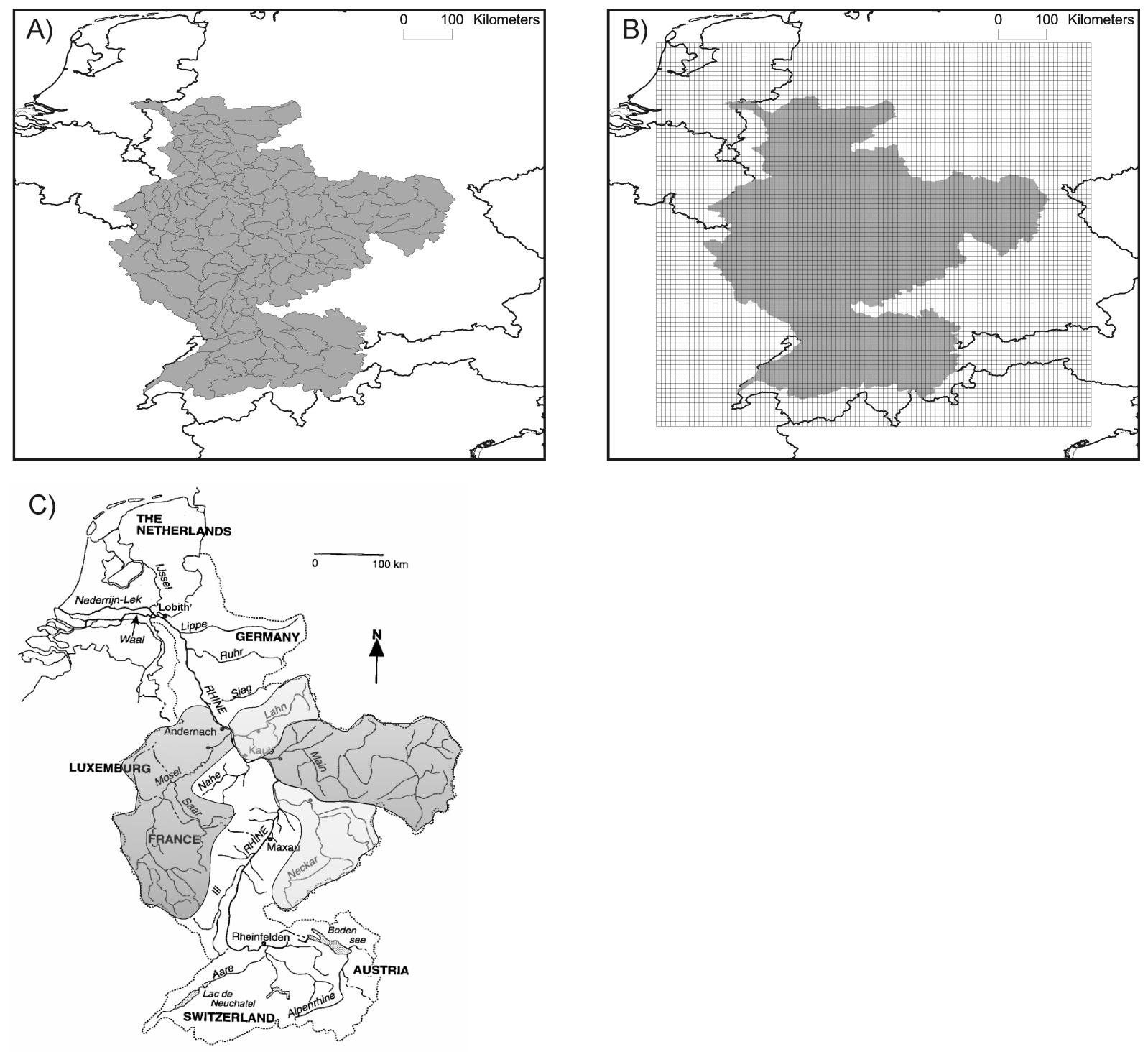

Fig. 1. Map of the Rhine basin showing (a) $134 \mathrm{HBV}$ sub-catchments; (b) the calculation grid used in VIC $(0.05 \times 0.05$ degree); and (c) discharge measurement locations and sub-basins used in the analysis.

cover in the Alps is characterized by agricultural land in the lower regions and by forest, shrubs, meadows, unvegetated areas and glaciers on the higher slopes. The area of the Upper Rhine between Basel and Bingen is hilly, with elevations reaching over $1000 \mathrm{~m}$ a.s.l., but with flood plains along the main rivers. In the flood plains there is urban development, while the hills are mainly forested. The main tributaries Neckar, Main, Moselle, Lahn and Sieg have a mixed land use pattern, with agriculture and vineyards on the valley slopes, and forest on the hillslopes and mountains. The Middle Rhine has incised in higher grounds, which resulted in a deep narrow valley without floodplains. The relatively flat and low-lying Lower Rhine area downstream of Cologne until the Dutch-German border is an urbanized area with a mixture of agriculture, meadows and some forest. Overall, the Rhine basin is densely settled, with an average population density of 270 persons per $\mathrm{km}^{2}$ (Earle, 2001). About $50 \%$ of the basin is used for agriculture, $15-20 \%$ is urban or suburban land, and the remainder is forest and otherwise natural lands (Wessel, 1995). The average discharge of the Rhine at Lobith is $2206 \mathrm{~m}^{3} / \mathrm{s}(1989-1995)$. The mean annual maximum discharge is $7473 \mathrm{~m}^{3} / \mathrm{s}$, while the maximum discharge in the period since 1961 is $11885 \mathrm{~m}^{3} / \mathrm{s}$, which occurred in January 1995 and caused floods in Germany. Parts of the Netherlands where evacuated, but against expectations the dikes held. Earlier considerable and some catastrophic floods in history are 1421, 1845, 1882 and 1926 (Disse and Engel, 2001). The surface area of the sub-basins under considera- 
tion in the present study vary from $5304 \mathrm{~km}^{2}$ to $27142 \mathrm{~km}^{2}$, as can be seen from Table 1 among other basin characteristics.

\section{Methods}

\subsection{Data}

Both the HBV and VIC models were forced using downscaled ECMWF ERA15 atmospheric re-analysis data, which is provided by the Max Planck Institute for Meteorology (MPI), Hamburg, Germany. The regional climate model REMO (Jacob, 2001) was used for downscaling and this dataset will be further referred to as ERA15. The ERA15 data set comprises the years 1993 through 2003, at a 3-hourly time step, with a grid resolution of 0.088 degrees and provides the following forcing data: precipitation, temperature, specific humidity, air pressure, downward radiation (shortwave and longwave) and windspeed. These input data are all required to run the VIC model.

To compare this data to observations, two additional meteorological datasets are available. First, a historical data set is available from the International Commission for the Hydrology of the Rhine basin (CHR). This data set is referred to as CHR and contains daily values of precipitation and temperature for the years 1961 through 1995, which are based on 36 measurement stations throughout the basin (Sprokkereef, 2001). Second, a historical dataset using interpolated measured data is available from the Climate Research Unit (CRU) where they develop a number of global datasets widely used in climatic research. This data set is referred to as CRU (Mitchell and Jones, 2005) and contains precipitation and temperature values at a monthly time step and comprises the years 1900 through 1998, with a grid resolution of 0.5 degrees.

HBV was also forced by CHR precipitation and temperature data and VIC only by CHR precipitation. VIC could not be forced by CHR temperature, because the models needs daily variation of temperature and therefore requires 3 or 6 hourly values of minimum and maximum temperature data. HBV only needs daily values of these forcing parameters, and at least monthly mean values of potential evaporation as input data. As a consequence of the detailed data input requirements of the VIC model, the ERA15 data still provided the remaining forcing parameters in combination with the CHR precipitation values. Combining measured values with RCM output data disturbs the water balance of the RCM output. It creates a figurative, but false forcing data set. Precipitation values of the CRU data set were only used for comparison of forcing data.

Additional spatial information on altitude, soil types and land cover is derived from a GIS database available at Federal Institute of Hydrology in Germany (Eberle et al., 2005). Historical discharge data was provided by the Dutch gov- ernmental Institute for Inland Water Management and Waste Water Treatment (RIZA).

\subsection{Forcing data comparison}

Rainfall amounts of the three forcing datasets were compared for the period of 1993-1995; the only three years the three datasets all overlap. A first comparison was made for basin wide mean values at a daily basis between the ERA15 and CHR values. For the second comparison, the ERA15 and CHR data sets were aggregated to weekly and monthly values and then compared to the CRU data.

\subsection{Model performance}

\subsubsection{Calibration at Lobith}

As is explained in Sect. 4.1, HBV and VIC were forced both by ERA15 and CHR precipitation values for comparison reasons. For VIC this results in a forcing data set containing a combination of measured data for precipitation and RCM output for the remaining seven input parameters. This forcing dataset is considered incorrect and therefore both models were calibrated using only ERA15 output.

We forced both models with ERA15 data and calibrated for the discharge gauge at the Dutch-German border at Lobith (see Fig. 1c) using observed discharge at Lobith for the year 1993. Only one year was used in order to limit the amount of calibration time for the VIC model. Because 1993 contains a relatively dry summer, as well as an extreme peak in winter, it was considered representative of the extremes for the total period. The model simulations were initialized using model states of October 1993 and also the first two months of 1993 are considered as a "warm-up" period, hence model results for this period were not used in the calibration process.

To calibrate VIC, former applications of VIC (Liang et al., 1994) were followed in that seven parameters were selected for calibration using an automated approach. These seven parameters describe the layer depths, relations between soil moisture content and baseflow and the infiltration capacity. For a complete description, see Hurkmans (2008).

The original calibration process for the HBV model of the Rhine basin is described by Eberle (2005). HBV was recalibrated for the year 1993 in a stepwise approach using the ERA15 dataset. Based on results of a parameter sensitivity analysis by Passchier and Stone (2003), for HBV, only the parameters $f c$ (field capacity that represents the total water storage capacity of the soil) and $k h q$ (describing the quick runoff function) were adjusted for recalibration.

\subsubsection{Sub-basin scale validation performance}

The calibrated models are validated using the remaining period of the ERA15 data set, the years 1994 through 2003. There is a large number of efficiency criteria to 
Table 1. Basin and sub-basin characteristics. Surface area $\left(\mathrm{km}^{2}\right)$ is defined by the basin area upstream of the gauging station.

\begin{tabular}{llllllll}
\hline Basin & Gauge & $\begin{array}{l}\text { Surface area } \\
\left(\mathrm{km}^{2}\right)\end{array}$ & $\begin{array}{l}\text { Mean Q } \\
\left(\mathrm{m}^{3} \mathrm{~s}^{-1}\right)\end{array}$ & $\begin{array}{l}\text { Min. Q } \\
\left(\mathrm{m}^{3} \mathrm{~s}^{-1}\right)\end{array}$ & $\begin{array}{l}\text { Max. Q } \\
\left(\mathrm{m}^{3} \mathrm{~s}^{-1}\right)\end{array}$ & $\begin{array}{l}\text { Mean annual } \\
\text { max. Q }\left(\mathrm{m}^{3} \mathrm{~s}^{-1}\right)\end{array}$ & Data period \\
\hline Rhine & Lobith & 160800 & 2206 & 788 & 11885 & 7473 & $1989-2005$ \\
Rhine & Andernach & 139549 & 2116 & 618 & 10406 & 6494 & $1961-2004$ \\
Mosel & Cochem & 27088 & 334 & 10 & 4020 & 2190 & $1961-2004$ \\
Lahn & Kalkofen & 5304 & 48 & 0 & 730 & 364 & $1961-2004$ \\
Main & Raunheim & 27142 & 176 & 44 & 1991 & 1043 & $1989-2005$ \\
Neckar & Rockenau & 12710 & 141 & 3 & 2105 & 1133 & $1971-1990$ \\
Rhine & Maxau & 50624 & 1297 & 379 & 4430 & 3191 & $1961-2004$ \\
\hline
\end{tabular}
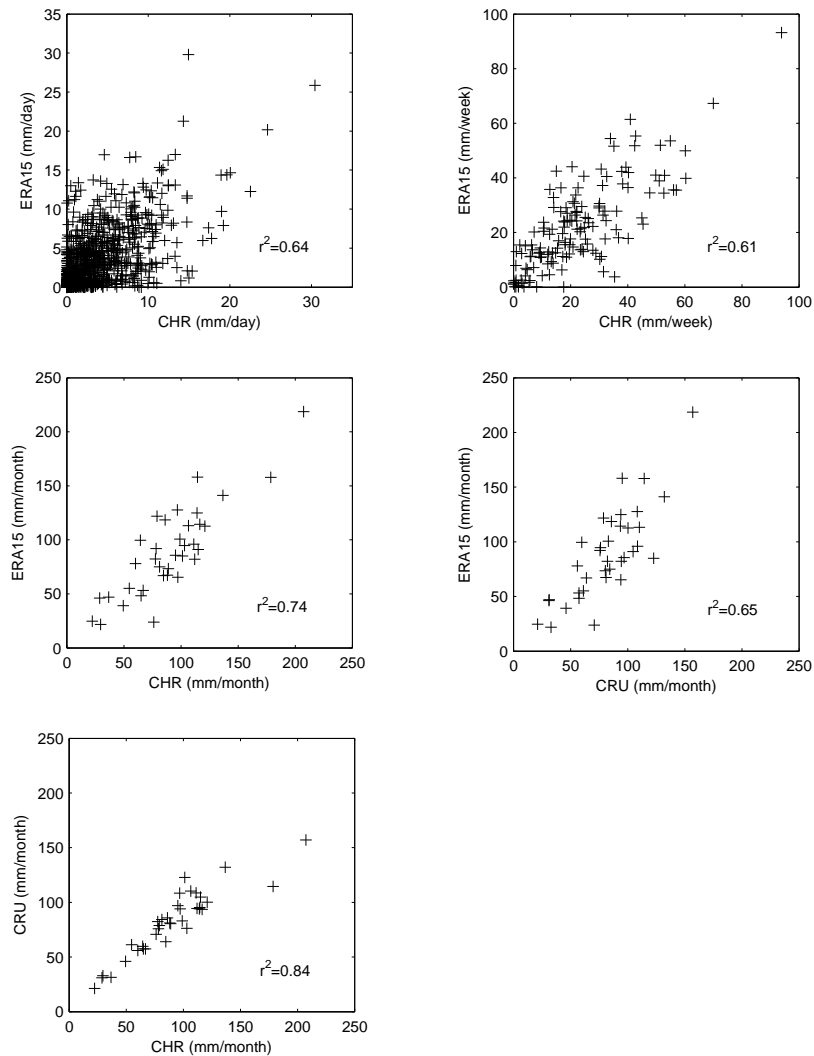

Fig. 2. ERA15 versus CHR versus CRU precipitation. The period 1993-1995 was used for the comparison.

choose from for model validation, such as those presented by Krause (2005) and each criterion may place different emphasis on different types of simulated and observed behaviours. The objective performance criteria used in the current study to compare the integral time series for the locations, are the coefficient of efficiency $(E)$ (Nash and Sutcliffe, 1970), the coefficient of determination $\left(r^{2}\right)$ and the volume error $(V E)$.

Model performance differs with the scale on which it is applied. In the present study we are interested in discharges at Lobith (the outlet of the basin), discharges upstream in the main Rhine channel and model performance at the sub-basin scale. The discharge gauges that were used in the analysis are Lobith, Andernach and Maxau along the Rhine branch, and tributary gauging stations at Cochem (Moselle), Kalkofen (Lahn), Raunheim (Main) and Rockenau (Neckar). These locations are shown in Fig. 1 and characteristics of the subbasins upstream of those gauges are presented in Table 1.

\subsubsection{Peak flows and low flows}

Periods with extreme discharges are often of most interest both in impact studies and real time flow predictions. A good representation by the model of the absolute amount, the timing and duration of the peak and low flows is very relevant. Subsequently, just for the gauge at Lobith, we selected five peak flow and five low flow periods, and chose additional performance indicators that relate to magnitude and timing of peak flows, together with minimum values and duration of low flows. These indicators are observed maximum discharge (max. $Q_{\mathrm{obs}}$ ), relative difference between observed and simulated maximum discharge $\left(d \max . Q_{\text {sim }}\right)$, difference in peak timing $(d T)$, observed minimum discharge (min. $Q_{\text {obs }}$ ), relative difference between observed and simulated minimum discharge ( $d$ max. $\left.Q_{\text {sim }}\right)$ and duration of the low flow period under a threshold of $1300 \mathrm{~m}^{3} / \mathrm{s}$ (DUT). A discharge of $1300 \mathrm{~m}^{3} / \mathrm{s}$ at Lobith is a critical value in summer periods; lower discharges affect shipping industry, agricultural supply, electricity production and drinking water supplies.

\section{Results}

\subsection{Forcing data comparison}

The difference between measured precipitation data (CHR and CRU) and reanalysis data (ERA15) provides an indication for the error or bias in the reanalysis data set. The assumption here is that measured data better represents actual values than reanalysis data and to test this assumption both 
Table 2. Performance criteria daily and monthly discharge values at Lobith for the calibration period (March 1993-December 1993) and the validation period (1994-2003).

\begin{tabular}{llcccc}
\hline & & \multicolumn{2}{c}{ Calibration period } & \multicolumn{2}{c}{ Validation period } \\
& & daily & monthly & daily & monthly \\
\hline E & VIC ERA15 & 0.47 & 0.26 & 0.31 & 0.40 \\
& HBV ERA15 & 0.49 & -0.08 & 0.62 & 0.60 \\
& VIC CHR & 0.44 & 0.35 & - & - \\
& HBV CHR & 0.85 & 0.73 & - & - \\
r2 & VIC ERA15 & 0.64 & 0.58 & 0.54 & 0.67 \\
& HBV ERA15 & 0.75 & 0.54 & 0.65 & 0.64 \\
& VIC CHR & 0.81 & 0.88 & - & - \\
& HBV CHR & 0.97 & 0.96 & - & - \\
VE & VIC ERA15 & 0.23 & 0.23 & 0.08 & 0.08 \\
& HBV ERA15 & 0.32 & 0.32 & -0.04 & -0.04 \\
& VIC CHR & -0.55 & -0.55 & - & - \\
& HBV CHR & 0.19 & 0.19 & - & - \\
\hline
\end{tabular}

measured datasets are compared with ERA15 data. Figure 2 illustrates the correlation between the precipitation data at different time steps. Daily values of ERA15 and CHR correlate poorly $\left(r^{2}=0.41\right)$ while the correlation coefficient increases with increasing time step length. The precipitation values of the ERA15 data do not show a constant bias that can be corrected. The correlation between monthly values of ERA15 and CHR is reasonably well $\left(r^{2}=0.74\right)$ and slightly higher than between ERA15 and CRU $\left(r^{2}=0.65\right)$. The correlation between CHR and CRU, however, has an $r^{2}$ value of 0.84 , which indicates that these two databases are most alike and that ERA15 probably has a larger error than the measured data.

\subsection{Model performance}

\subsubsection{Calibration and validation period at Lobith}

Daily values of all performance criteria for Lobith are displayed in Table 2, where a distinction is made between the calibration and the validation period. The additional six locations will be discussed in Sect. 5.2.2. At Lobith after calibration, the results of the HBV model forced with ERA15 show a moderate performance $\left(E=0.49, r^{2}=0.75\right)$, whereas the VIC model fits less well $\left(E=0.47, r^{2}=0.64\right)$. This is mainly caused by an overestimation of the volume, by $23 \%$ (VIC) and 32\% (HBV), respectively. VIC forced by CHR shows an increased correlation $\left(r^{2}=0.81\right)$ when compared to its performance when forced by ERA15, but a decrease on the other performance criteria $(E=0.44, V E=-0.55)$. However, the HBV model forced with CHR fits well when compared to observed discharges $\left(E=0.85, r^{2}=0.97\right)$.

Figure 4 depicts the results of the period 1993-2003 at Lobith, respectively for the VIC and the HBV models both forced with ERA15 data. The HBV model shows a bet-

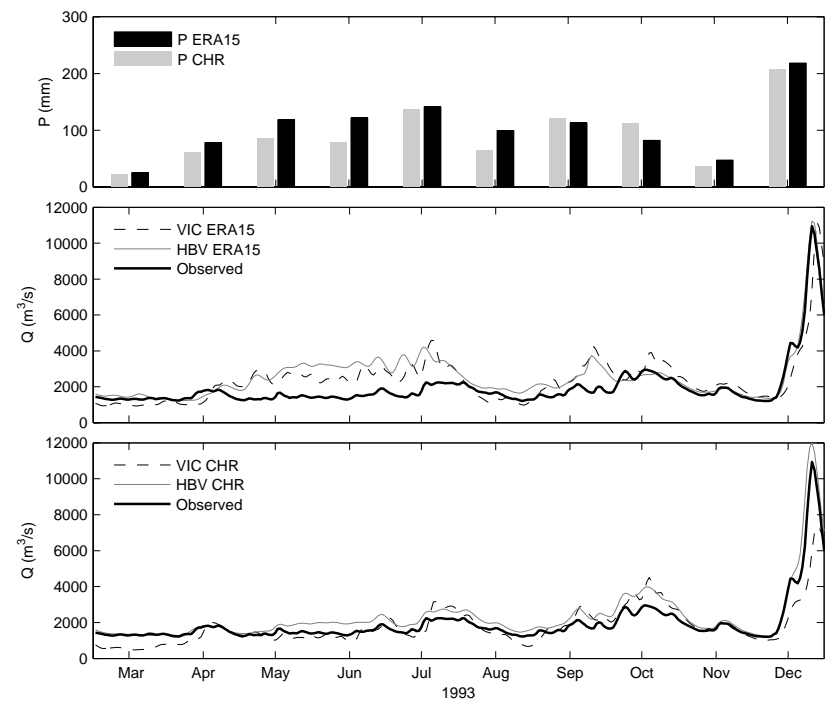

Fig. 3. Monthly precipitation values for the Rhine basin according to different datasets (top) and daily discharge values at Lobith (bottom); model simulation results for the calibration period compared to the observed discharge in the period March-December 1993.
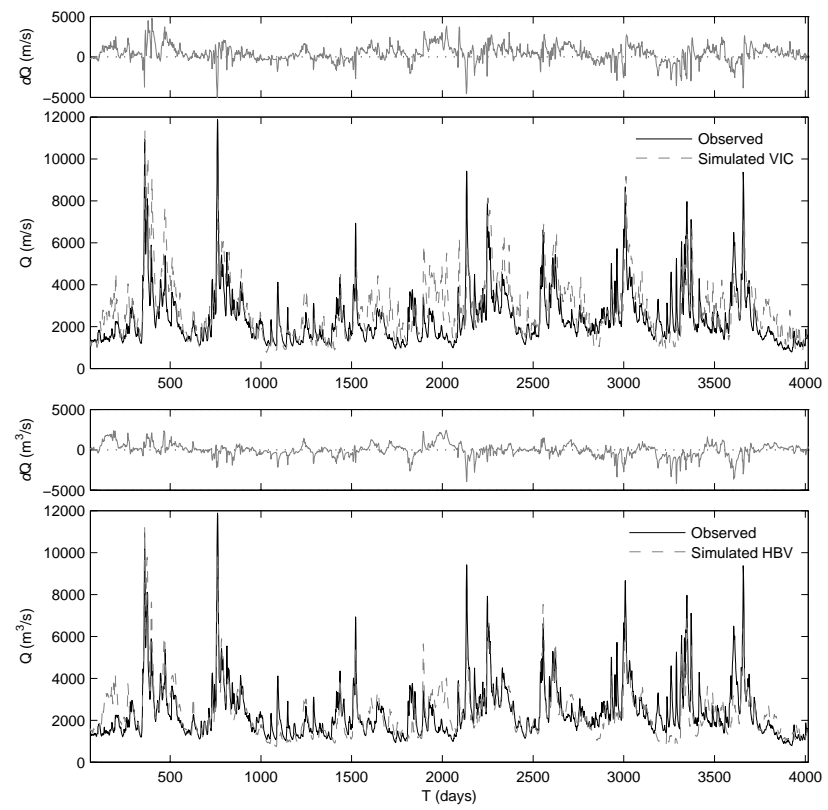

Fig. 4. Daily simulation results of the HBV model (a) and the VIC model (b) compared to the observed river discharge for the period 1993-2003 (4017 days).

ter fit of the simulated discharge to the observed discharge than VIC, which is confirmed by the efficiency coefficients as shown in Table 2. The coefficient of efficiency $(E)$ of HBV is 0.62 , where VIC shows 0.31 and coefficient of determination $\left(r^{2}\right)$ of HBV is 0.65 , where VIC displays 0.54 . The volume error of both models is low $(-4 \%$ by HBV and $8 \%$ 
Table 3. Observed and simulated mean, minimum and maximum discharge (in $\mathrm{m}^{3} / \mathrm{s}$ ), their standard deviation $(S D)$ and skewness for the period March 1993 through December 2003.

\begin{tabular}{|c|c|c|c|c|c|c|c|}
\hline Basin & Gauge & & $\begin{array}{l}\text { Mean } Q \\
\left(\mathrm{~m}^{3} / \mathrm{s}\right)\end{array}$ & $\begin{array}{l}\operatorname{Min} Q \\
\left(\mathrm{~m}^{3} / \mathrm{s}\right)\end{array}$ & $\begin{array}{l}\operatorname{Max} Q \\
\left(\mathrm{~m}^{3} / \mathrm{s}\right)\end{array}$ & $\begin{array}{l}S D \\
\left(\mathrm{~m}^{3} / \mathrm{s}\right)\end{array}$ & $\begin{array}{l}\text { Skewness } \\
(-)\end{array}$ \\
\hline \multirow[t]{3}{*}{ Rhine } & Lobith & Observed & 2387 & 788 & 11885 & 1300 & 2.29 \\
\hline & & VIC & 2811 & 773 & 11394 & 1468 & 1.45 \\
\hline & & HBV & 2339 & 746 & 11228 & 1244 & 1.99 \\
\hline \multirow[t]{3}{*}{ Rhine } & Andernach & Observed & 2197 & 630 & 10500 & 1182 & 2.29 \\
\hline & & VIC & 2474 & 734 & 10487 & 1258 & 1.46 \\
\hline & & $\mathrm{HBV}$ & 2054 & 593 & 11092 & 1104 & 2.08 \\
\hline \multirow[t]{3}{*}{ Mosel } & Cochem & Observed & 355 & 31 & 4020 & 416 & 3.20 \\
\hline & & VIC & 325 & 49 & 2463 & 282 & 2.63 \\
\hline & & HBV & 263 & 21 & 3644 & 274 & 4.37 \\
\hline \multirow[t]{3}{*}{ Lahn } & Kalkofen & Observed & 48 & 0 & 598 & 61 & 3.86 \\
\hline & & VIC & 42 & 6 & 350 & 42 & 2.44 \\
\hline & & $\mathrm{HBV}$ & 33 & 1 & 506 & 40 & 4.21 \\
\hline \multirow[t]{3}{*}{ Main } & Raunheim & Observed & 183 & 51 & 1,991 & 197 & 3.65 \\
\hline & & VIC & 234 & 39 & 1885 & 227 & 2.48 \\
\hline & & $\mathrm{HBV}$ & 180 & 44 & 1946 & 189 & 3.89 \\
\hline \multirow[t]{3}{*}{ Neckar } & Rockenau & Observed & 150 & 27 & 2140 & 142 & 5.26 \\
\hline & & VIC & 216 & 34 & 2490 & 201 & 3.17 \\
\hline & & HBV & 144 & 19 & 2291 & 167 & 4.93 \\
\hline \multirow[t]{3}{*}{ Rhine } & Maxau & Observed & 1322 & 400 & 4330 & 530 & 1.38 \\
\hline & & VIC & 1631 & 374 & 5222 & 739 & 0.98 \\
\hline & & HBV & 1335 & 407 & 5137 & 629 & 1.18 \\
\hline
\end{tabular}

by VIC). A visual analysis of the hydrographs at multiple peak flow events, shows that both models simulate the recession curve well. Errors arise at most extreme peak events (see Sect. 5.2.3 on peak flows and low flows) where the quick flow component either is too small or too large. VIC tends to overestimate more peaks than HBV does and shows a delayed peak at many peak events. Medium flows are mostly well represented by HBV, whereas VIC substantial over estimates discharges, sometimes for a period of several months. Low flow periods are simulated well for a length of time up to 2 or 3 months, and when drought periods are more lengthy, both models tend to underestimate baseflow (see Sect. 5.2.3). The changeable reaction of both models to different meteorological conditions suggests that the storage capacity in the upper layers is very irregular, resulting in variable estimates of direct runoff. Also, the depletion factor controlling drainage from the lower layers seems to be too large during lengthy drought events. A further explanation for these moderately successful results might be that at a short time step like a daily basis, errors in timing of simulated high and low flows have a considerable negative influence on the performance indicators. Nonetheless, when monthly values of simulated discharge are evaluated they display similar or slightly worse results, as can be seen from Table 2; VIC and HBV forced with ERA15 perform moderate and HBV forced with CHR fits well, which is about equal to the HBV simu- lations at a daily basis. The difference in coefficient of efficiency $(E)$ between daily and monthly values of the HBV model forced with ERA15 in the calibration period stands out though, a moderate 0.49 for daily values and a dramatic -0.08 for monthly values. Instead of the expected damping effect on performance, aggregating to a bigger time step indeed causes the observed and modelled peak value of several days in December 1993 (shown in Fig. 3) to damp, but does not effect the more or less consistent over estimation during the months May until July. Since the coefficient of efficiency $(E)$ is sensitive to peak values, in this case the absolute observed and modelled discharge values are damped, but the relative error by time step increases which causes the coefficient to drop. These results indicate that forcing data largely influence the performance values of both models. A closer examination of the precipitation values in both forcing data sets during the calibration period is depicted in Fig. 3, together with observed and simulated discharge values. The figure shows that during the months May, June and July, both HBV and VIC forced with ERA 15 consistently overestimate discharge by $25-100 \%$, whereas HBV forced with CHR also overestimates discharge, but to a lesser degree. VIC forced by CHR shows an even better fit for these months. This can be explained by the equally consistent higher ERA15 precipitation values when compared to the CHR data. In $\mathrm{Au}-$ gust, ERA15 again displays higher values than the CHR data, 
Table 4. Performance criteria daily discharge values. $k m r$ represents the length of the Rhine from the Bodensee.

\begin{tabular}{|c|c|c|c|c|c|c|c|c|}
\hline \multicolumn{9}{|c|}{ Calibration period } \\
\hline & \multirow{2}{*}{$k m r$} & 857 & 613 & 592 & 586 & 497 & 428 & 363 \\
\hline & & Lobith & Andernach & Cochem & Kalkofen & Raunheim & Rockenau & Maxau \\
\hline \multirow[t]{4}{*}{$E$} & VIC ERA15 & 0.47 & 0.52 & 0.45 & 0.24 & 0.64 & -0.16 & -1.20 \\
\hline & HBV ERA 15 & 0.49 & 0.59 & 0.81 & 0.30 & 0.60 & 0.31 & -0.40 \\
\hline & VIC CHR & 0.44 & 0.68 & 0.63 & 0.50 & 0.46 & 0.14 & 0.64 \\
\hline & HBV CHR & 0.85 & 0.91 & 0.92 & 0.86 & 0.89 & 0.77 & 0.78 \\
\hline \multirow[t]{4}{*}{$r^{2}$} & VIC ERA15 & 0.64 & 0.61 & 0.57 & 0.50 & 0.76 & 0.40 & 0.47 \\
\hline & HBV ERA15 & 0.75 & 0.75 & 0.82 & 0.37 & 0.83 & 0.48 & 0.54 \\
\hline & VIC CHR & 0.81 & 0.81 & 0.69 & 0.67 & 0.78 & 0.52 & 0.71 \\
\hline & HBV CHR & 0.97 & 0.97 & 0.95 & 0.86 & 0.96 & 0.88 & 0.95 \\
\hline \multirow[t]{4}{*}{$V E$} & VIC ERA15 & 0.23 & 0.14 & -0.31 & -0.49 & 0.43 & 0.50 & 0.27 \\
\hline & HBV ERA 15 & 0.32 & 0.23 & 0.17 & -0.31 & 0.62 & 0.28 & 0.22 \\
\hline & VIC CHR & -0.55 & -0.07 & -0.14 & -0.52 & -0.34 & 0.06 & -0.41 \\
\hline & HBV CHR & 0.19 & 0.10 & 0.13 & -0.08 & 0.21 & 0.12 & 0.09 \\
\hline \multicolumn{9}{|c|}{ Validation period } \\
\hline & \multirow[t]{2}{*}{$k m r$} & 857 & 613 & 592 & 586 & 497 & 428 & 363 \\
\hline & & Lobith & Andernach & Cochem & Kalkofen & Raunheim & Rockenau & Maxau \\
\hline \multirow[t]{2}{*}{$E$} & VIC ERA15 & 0.31 & 0.30 & 0.38 & 0.32 & 0.05 & -0.46 & -0.62 \\
\hline & HBV ERA 15 & 0.62 & 0.55 & 0.48 & 0.44 & 0.07 & 0.17 & 0.28 \\
\hline \multirow[t]{2}{*}{$r^{2}$} & VIC ERA15 & 0.54 & 0.48 & 0.43 & 0.43 & 0.27 & 0.32 & 0.39 \\
\hline & HBV ERA15 & 0.65 & 0.60 & 0.56 & 0.51 & 0.23 & 0.45 & 0.49 \\
\hline \multirow[t]{2}{*}{$V E$} & VIC ERA15 & 0.08 & 0.02 & -0.25 & -0.36 & 0.02 & 0.21 & 0.18 \\
\hline & HBV ERA15 & -0.04 & -0.09 & -0.29 & -0.31 & -0.05 & -0.07 & -0.01 \\
\hline
\end{tabular}

while observed and simulated discharge agree quite well. This lack of reaction in modelled discharge in August can be explained by higher evaporation values during summer than spring, which neutralize the precipitation surplus, next to the fact that absolute precipitation values are lower in summer than in springtime.

\subsubsection{Sub-basin scale performance}

Several statistical parameters for the complete simulation period are presented in Table 3. The mean and minimum simulated discharges agree reasonable well for the HBV model, whereas VIC overestimates those values, except for the gauges at Cochem and Kalkofen. The maximum discharges, though, are underestimated for most locations, except for the most upstream gauges Rockenau and Maxau. The values for the standard deviation (SD) based on daily values are high for both simulated and observed values. This can be explained by the skewed distribution of the discharge values. Based on this information it can be concluded that the probability density function of the observed values at Lobith is best represented by the simulated discharges by HBV.

For the remaining six gauges upstream of Lobith, scatter plots of the daily observed and simulated discharges are displayed (Fig. 5) for the validation period. The accessory $r^{2}$ values are presented in Table 4 . Tables 4 and 5 show the results of all performance criteria for daily and monthly values respectively, for all locations. Above the location name, the $k m r$ number is displayed. This number represents the length of the Rhine from the Bodensee in Switzerland and Germany. For example, the gauging station at Lobith is located $857 \mathrm{~km}$ downstream form the Bodensee. In the current study, the gauges that are not located exactly along the Rhine, but along tributaries draining the sub-basins, have kmr numbers that represent locations where the side rivers enter the Rhine. The $k m r$ number is used to illustrate all performance criteria as presented in Tables 4 and 5 , in a graphical way in Figs. 6 and 7. In Fig. 7, the volume error is not displayed, since the volume error does not change when the time step is adjusted (see Tables 4 and 5).

The Nash and Sutcliffe efficiency coefficient $(E)$ decreases in the upstream direction, sometimes even below zero at Rockenau and Maxau for VIC results. An efficiency lower than zero indicates that the mean value of the observed time series would have been a better predictor than the model. From all graphs on the left side representing the calibration period, it is obvious that $\mathrm{HBV}$ forced with $\mathrm{CHR}$ performs considerably better than VIC forced with CHR and than both models forced with ERA15. Nonetheless, VIC forced with CHR performs better than VIC forced with ERA15, especially in upstream direction. Moreover, for the ERA15 forcing, HBV performs marginally better than VIC at a daily 

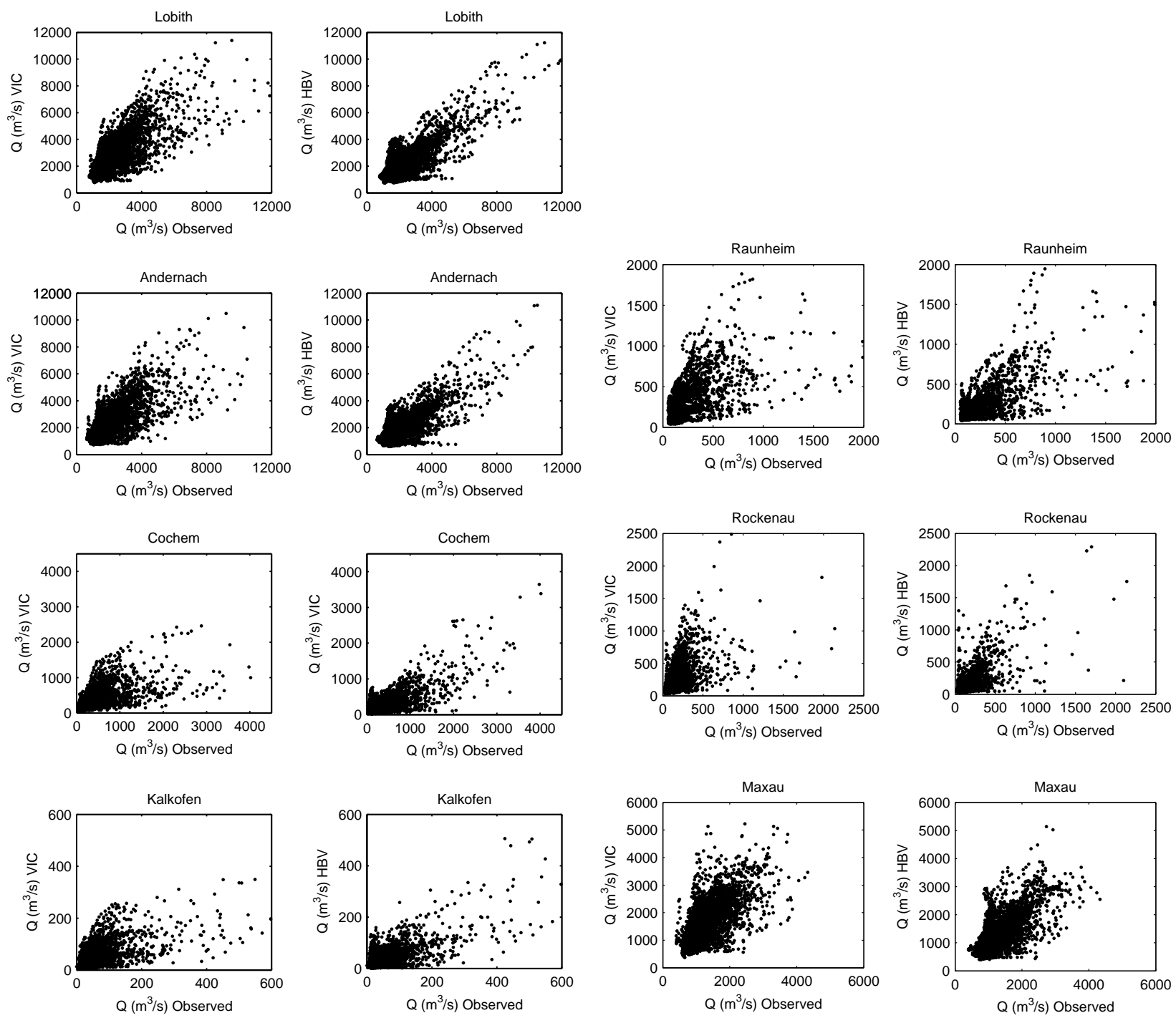

Fig. 5. Scatter plots of observed and simulated discharge $Q\left(\mathrm{~m}^{3} / \mathrm{s}\right)$ at a daily basis. The results for VIC are displayed on the left side and for HBV on the right side.

basis, whereas VIC performs marginally better than HBV at a monthly basis. When studying the validation period on the right side, however, HBV performs substantially better than VIC, which indicates that HBV is more robust in its performance.

\subsubsection{Peak flows and low flows}

Table 6 shows the five highest daily discharges and the five lowest monthly discharges, as observed and simulated at Lobith. Observed volumes over threshold and maximum peak discharges reveal that both models overestimate and underestimate the same peaks. Furthermore, it shows that VIC tends to delay flood peaks, for some peaks even up to 6 days, while HBV simulates the timing of the peaks very well. Two factors in VIC explain this delaying of peak flows: first, the routing algorithm that is used in VIC might delay ar- rival at Lobith slightly compared to the internal routing algorithm in HBV. This was also noted in Hurkmans et al. (2008) where runoff from another conceptual water balance model (STREAM) was routed with different algorithms. Second, the degree to which peaks are delayed also depends on calibration parameters, particularly depths of the upper layers and the infiltration capacity factor (see for details on VIC calibration Hurkmans et al., 2008). When the resulting infiltration capacity is higher, there is less direct runoff and, in case of near-saturation, excess water is, with a small delay, transported as baseflow. For the peak of 1993, which is included in the calibration period, the simulated timing by VIC was rather accurate, however, for other peaks in the validation period these parameter settings were apparently less applicable. 

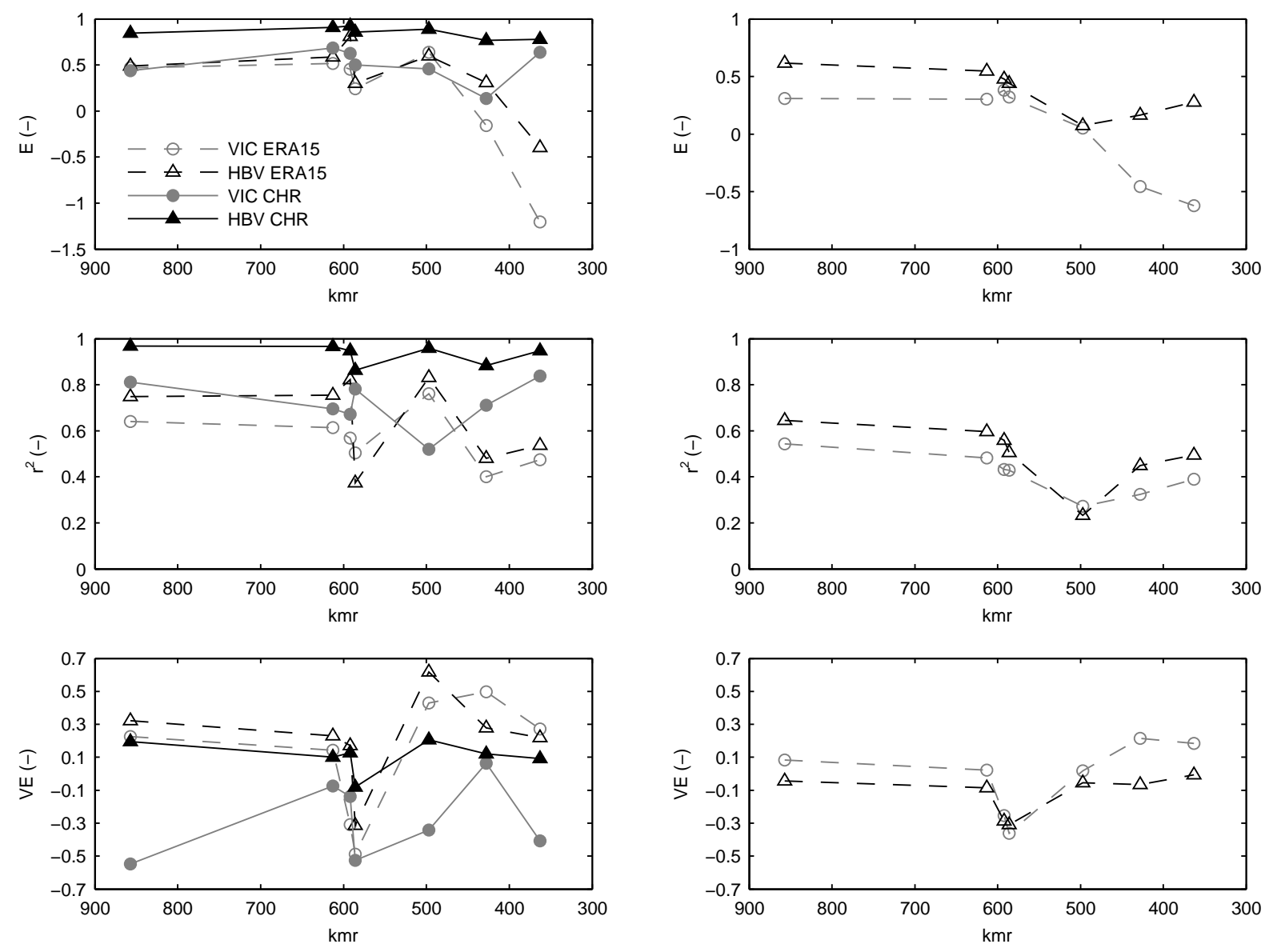

Fig. 6. Performance criteria daily discharge values. $k m r$ represents the length of the Rhine from the Bodensee. The calibration period is displayed at the left side and the validation period at the right side.

Concerning the low flows, VIC tends to underestimate the minimum values and HBV tends to overestimate the low flows under consideration. For the duration of the most extreme low flows below a threshold of $1300 \mathrm{~m}^{3} / \mathrm{s}$, both models underestimated the duration of the low flows significantly and showed variable performance on the less extreme low flow periods.

\section{Discussion and conclusions}

In the view of the utility of hydrological models in climate scenario studies, the goal of this paper was to compare the hydrological models HBV and VIC by testing their performance for simulating historical discharge in the Rhine basin. These models have different model structures and there is no consensus in research on rainfall-runoff modelling on what model structure is to be preferred. Some research suggest, however, that the VIC approach more accurately simulates the timing of peak discharges (Troy et al., 2007). Different meteorological data sets were used as model input and HBV and VIC were compared at both basin and sub-basin scale using various performance criteria. Furthermore, simulated peak flows and low flows were compared.

We have seen that the performance of both models was less in upstream basins than at the basin outlet (gauging station Lobith), but that for all upstream basins HBV still performed better than VIC at a daily basis. We have seen that HBV was more robust when the performance of the calibration period ( $E=0.49, r^{2}=0.75$ vs. $E=0.47, r^{2}=0.64$ at Lobith) and the validation period $\left(E=0.62, r^{2}=0.65\right.$ vs. $E=0.31, r^{2}=0.54$ at Lobith) were compared. In addition, HBV forced with CHR data $\left(E=0.85, r^{2}=0.97\right.$ for the calibration period at Lobith) performed much better than VIC forced with CHR ( $E=0.44$, $\left.r^{2}=0.81\right)$ and than both VIC and HBV forced with ERA15.

For the most extreme peak flows, HBV simulated maximum discharges best $\left(d \max . Q_{\text {sim }}\right.$ HBV $1-17 \%, d$ max. $Q_{\text {sim }}$ VIC 2-27\%), while VIC performed better at the moderate peak flows $\left(d\right.$ max. $Q_{\text {sim }}$ HBV $21-35 \%, d$ max. $Q_{\text {sim }}$ VIC $13-35 \%)$. Besides simulating measured values of discharges, timing of peak flows was investigated. It appeared that VIC displayed several days delay in estimating timing of the peak 

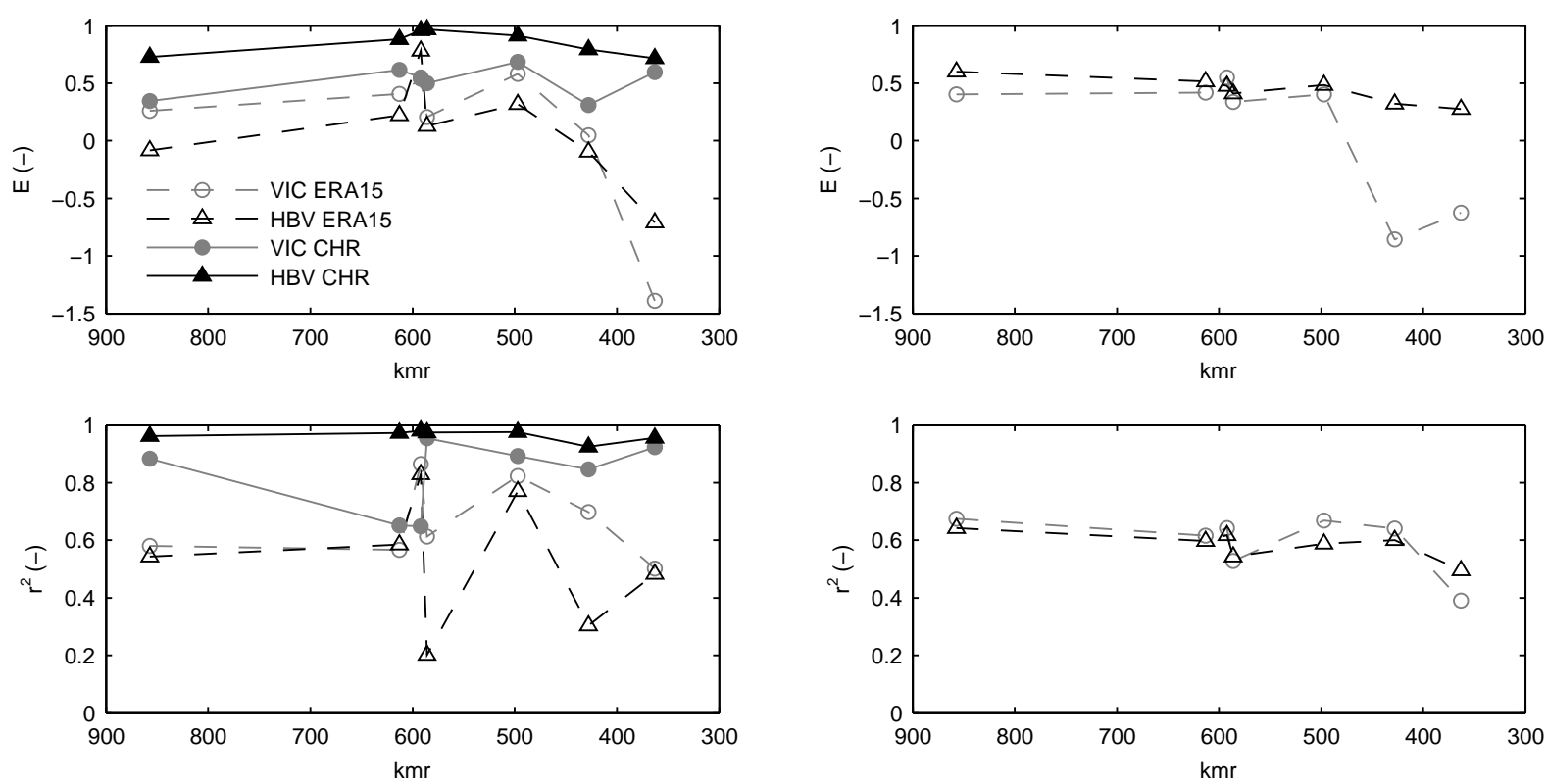

Fig. 7. Performance criteria monthly discharge values. $k m r$ represents the length of the Rhine from the Bodensee. The calibration period is displayed at the left side and the validation period at the right side.

Table 5. Performance criteria monthly discharge values. $k m r$ represents the length of the Rhine from the Bodensee.

\begin{tabular}{|c|c|c|c|c|c|c|c|c|}
\hline \multicolumn{9}{|c|}{ Calibration period } \\
\hline & $k m r$ & 857 & 613 & 592 & 586 & 497 & 428 & 363 \\
\hline & & Lobith & Andernach & Cochem & Kalkofen & Raunheim & Rockenau & Maxau \\
\hline \multirow[t]{4}{*}{$E$} & VIC ERA15 & 0.26 & 0.41 & 0.54 & 0.21 & 0.58 & 0.05 & -1.39 \\
\hline & HBV ERA15 & -0.08 & 0.22 & 0.78 & 0.13 & 0.32 & -0.09 & -0.71 \\
\hline & VIC CHR & 0.35 & 0.61 & 0.55 & 0.50 & 0.68 & 0.31 & 0.59 \\
\hline & HBV CHR & 0.73 & 0.88 & 0.96 & 0.97 & 0.91 & 0.79 & 0.72 \\
\hline \multirow[t]{4}{*}{$r^{2}$} & VIC ERA15 & 0.58 & 0.57 & 0.86 & 0.61 & 0.82 & 0.70 & 0.50 \\
\hline & HBV ERA15 & 0.54 & 0.58 & 0.83 & 0.20 & 0.77 & 0.30 & 0.48 \\
\hline & VIC CHR & 0.88 & 0.65 & 0.65 & 0.95 & 0.89 & 0.85 & 0.92 \\
\hline & HBV CHR & 0.96 & 0.97 & 0.98 & 0.97 & 0.98 & 0.93 & 0.96 \\
\hline \multirow[t]{4}{*}{$V E$} & VIC ERA15 & 0.23 & 0.14 & -0.31 & -0.49 & 0.43 & 0.50 & 0.27 \\
\hline & HBV ERA15 & 0.32 & 0.23 & 0.17 & -0.31 & 0.62 & 0.28 & 0.22 \\
\hline & VIC CHR & -0.55 & -0.07 & -0.14 & -0.52 & -0.34 & 0.06 & -0.41 \\
\hline & HBV CHR & 0.19 & 0.10 & 0.13 & -0.08 & 0.21 & 0.12 & 0.09 \\
\hline \multicolumn{9}{|c|}{ Validation period } \\
\hline & \multirow[t]{2}{*}{$k m r$} & 857 & 613 & 592 & 586 & 497 & 428 & 363 \\
\hline & & Lobith & Andernach & Cochem & Kalkofen & Raunheim & Rockenau & Maxau \\
\hline \multirow[t]{2}{*}{$E$} & VIC ERA15 & 0.40 & 0.42 & 0.55 & 0.34 & 0.40 & -0.86 & -0.62 \\
\hline & HBV ERA15 & 0.60 & 0.52 & 0.48 & 0.41 & 0.48 & 0.32 & 0.28 \\
\hline \multirow[t]{2}{*}{$r^{2}$} & VIC ERA15 & 0.67 & 0.62 & 0.64 & 0.53 & 0.67 & 0.64 & 0.39 \\
\hline & HBV ERA15 & 0.64 & 0.60 & 0.62 & 0.54 & 0.59 & 0.60 & 0.49 \\
\hline \multirow[t]{2}{*}{$V E$} & VIC ERA15 & 0.08 & 0.02 & -0.25 & -0.36 & -0.03 & 0.22 & 0.18 \\
\hline & HBV ERA15 & -0.04 & -0.09 & -0.29 & -0.31 & -0.09 & -0.06 & -0.01 \\
\hline
\end{tabular}


Table 6. Analysis of peak flows and low flows at the outlet of the basin (Lobith), showing observed maximum discharge (max. $Q_{\text {obs }}$ ), relative difference between observed and simulated maximum discharge ( $d$ max. $\left.Q_{\text {sim }}\right)$, difference in peak timing $(d T)$, observed minimum discharge (min. $Q_{\mathrm{obs}}$ ), relative difference between observed and simulated minimum discharge ( $d$ max. $Q_{\text {sim }}$ ) and duration of the low flow period under a threshold of $1300 \mathrm{~m}^{3} / \mathrm{s}$ (DUT).

\begin{tabular}{llllll}
\hline Peak flows & $31 / 01 / 1995$ & $25 / 12 / 1993$ & $04 / 11 / 1998$ & $07 / 01 / 2003$ & $28 / 03 / 2001$ \\
\hline Max. $Q_{\text {obs }}\left(\mathrm{m}^{3} / \mathrm{s}\right)$ & 11775 & 11034 & 8410 & 9366 & 8666 \\
$d$ max. $Q_{\text {sim VIC }(\%)}$ & -26.7 & 1.5 & -35.1 & -15.5 & -12.5 \\
$d$ max. $Q_{\text {sim }}$ HBV $(\%)$ & -16.3 & 0.9 & -34.9 & -32.1 & -20.6 \\
$d T$ VIC (days) & 2 & 2 & 6 & 5 & 4 \\
$d T$ HBV (days) & 0 & 0 & 0 & -1 & -1 \\
\hline & & & & & \\
\hline Low flows & $09 / 2003$ & $11 / 1997$ & $08 / 1998$ & $09 / 1996$ & $03 / 1993$ \\
Min. $Q_{\text {obs }}$ (m $\left.{ }^{3} / \mathrm{s}\right)$ & 788 & 931 & 983 & 1077 & 1228 \\
$d$ min. $Q_{\text {sim VIC }(\%)}$ & -20.3 & -10.7 & 4.5 & -26.0 & -38.5 \\
$d$ min. $Q_{\text {sim }}$ HBV $(\%)$ & 18.7 & 6.5 & 44.4 & -15.8 & 0.5 \\
DUT $Q_{\text {obs }}$ (days) & 141 & 68 & 39 & 37 & 13 \\
DUT VIC (days) & 104 & 22 & 15 & 60 & 68 \\
DUT HBV (days) & 93 & 33 & 0 & 54 & 11 \\
\hline
\end{tabular}

discharge. Most low flows were underestimated by VIC, where HBV showed overestimation of the low flows. Also the performance of both models in reproducing duration of low flows was poor.

Hence, the semi-distributed lumped conceptual HBV model performed much better than the distributed land surface model VIC. This deflects from the general idea that more complex distributed modelling better represents observed discharges as compared to simple conceptual model approaches (Reggiani and Schellekens, 2003; Refsgaard, 1996). These results support the notion that even for a well documented river basin such as the Rhine, more complex modelling does not automatically lead to better results (Booij, 2003; Uhlenbrook, 2003).

We are convinced, though, that VIC should be able to perform better than it has done so far in the Rhine basin, and thus model performance might be improved (Hurkmans et al., 2008). The performance of VIC might increase using a longer calibration period and further refining the spatial distribution of adjusted parameters. Furthermore, by solving both the water and the energy balance VIC holds the potential to better describe soil-atmosphere feedback processes, if the model scheme were to be combined with an atmospheric model. In the line of small-scale hydrometeorology and modelling the effects of land use change, this is a conclusive reason for further development (Hurkmans et al., 2008). Moreover, VIC has performed well in the past, for example in studies by Liang et al. (1994) and Troy et al. (2007). But also the HBV model for the Rhine basin can be improved. Lake retention for example, is not implemented yet in both models. Especially concerning the Bodensee, a large upstream lake in the Rhine basin, this is a quite drastic simplification and an obvious potential for further improvement. We subscribe the recommendation of Seibert (1999), that model development and calibration is an undertaking that should not be carried out by a single researcher, but requires scientific dialogue.

The results also lead us to the conclusion that forcing data has a considerable influence on model performance, irrespectively to the type of model structure. It emphasizes the need for ground-based meteorological measurements and a suggestion might be to correct downscaled climate model reanalysis data such as ERA15, whenever measurements are available. It should be kept in mind that comparing mean values of precipitation and temperature provides little guide to the quality of the data during more extreme events that affect hydrological systems. Pitman and Perkins (2007), for example, propose a probability density function based assessment and a skill score that shows a climate model's ability to simulate the 95th rainfall percentile. Comprehensive comparison and correction of downscaled climate model output is a challenging task for further research.

The conclusion as to the application of hydrological models in climate scenario studies, then, is that for the Rhine basin HBV is preferred, since it has shown better overall performance and seems to be more robust than VIC. The extreme events were simulated best by HBV, which implies that $\mathrm{HBV}$ can provide the most reliable indication of possible future shifts in extreme events due to climate change. The more realistic representation of evaporation processes by VIC than HBV did not result in better performance even in the dry periods, when the evaporation volume is substantial in the water balance. The final advantage of HBV over VIC is that HBV has short computation times, which makes it suitable for simulating long time series of the many available different climate scenarios. 
Acknowledgements. This research was supported by the project ACER (A7) under the Dutch BSIK Climate Changes Spatial Planning program. We wish to thank H. Buiteveld from the Dutch Institute for Inland Water Management and Waste Water Treatment (RIZA) and the German Federal Institute of Hydrology (BfG) for both allowing the use of the HBV model, and providing meteorological and discharge measurement data. D. Jacob and E. Mazurkewitz from the Max Planck Institute for Meteorology are kindly acknowledged for providing meteorological data. Finally we thank two anonymous colleagues for occasional data editing and their constructive comments that helped to improve this paper.

Edited by: E. Todini

\section{References}

Abbott, M. B., Bathurs, J. C., Cunge, J. A., O’Connel, P. E., and Rasmussen, J.: An introduction to the european hydrological system - systeme hydrologique "She", 1: History and philosophy of a physically based distributed modelling system, J. Hydrol., 87, 45-59, 1986.

Bergström, S.: Development and application of a conceptual runoff model for scandinavian catchments, ph.D. Thesis, Department of water resources engineering, University of Lund, Lund, Sweden, 1976.

Bergström, S., Lindström, G., and Pettersson, A.: Multi-variable parameter estimation to increase confidence in hydrological modelling, Hydrol. Process., 16, 413-421, 2002.

Beven, K.: How far can we go in distributed hydrological modelling?, Hydrol. Earth Syst. Sci., 5, 1-12, 2001, http://www.hydrol-earth-syst-sci.net/5/1/2001/.

Beven, K.: Towards an alternative blueprint for a physically based digitally simulated hydrologic response modelling system, Hydrol. Process., 16, 189-206, 2002a.

Beven, K.: Towards a coherent philosophy for modelling the environment, Proc. R. Soc. Lond. A, 458, 1-20, 2002 b.

Bogaard, T. A., Luxemburg, W. M. J., De Wit, M., Douben, N., and Savenije, H. H. G.: Some hydrological challenges in understanding discharge generation processes in the Rhine and Meuse basins, Phys. Chem. Earth, 30, 262-266, 2005.

Booij, M. J.: Determination and integration of appropriate spatial scales for river basin modelling, Hydrol. Process., 17, 25812598, 2003.

Buishand, T. A. and Lenderink, G.: Estimation of future discharges of the river Rhine in the SWURVE project, KNMI, De Bilt, The Netherlands TR-273, 1-36, 2004.

De Roo, A. P. J., Wesseling, C. G. and Van Deursen, W. P. A. Physically based river basin modelling within a GIS. The LISFLOOD model. Proc. 3rd Int. Conf. on Geo-Computation. In: Geo-Computation CF-ROM produced by R. J. Abrahart, 1998.

De Roo, A. P. J., Wesseling, C. G. and Van Deursen, W. P. A. Physically based river basin modelling within a GIS. The LISFLOOD model. Hydrol. Process., 14, 1981-1992, 2000.

Disse, M. and Engel, H.: Flood events in the Rhine basin: Genesis, influendes and mitigation, Nat. Hazards, 23, 271-290, 2001.

The water page - the Rhine river: http://www.thewaterpage.com/ rhine_main.htm, access: 2 April 2007, 2001.
Eberle, M., Buiteveld, H., Wilke, K., and Krahe, P.: Hydrological modelling in the river Rhine basin part III - daily HBV model for the Rhine basin, Institute for Inland Water Management and Wase Water Treatment (RIZA) and Bundesanstalt für Gewässerkunde (BfG), Koblenz, Germany BfG-1451, 2005.

Hurkmans, R. T. W., De Moel, H., Aerts, J. C. J. H., and Troch, P. A.: Water balance versus land surface model in the simulation of Rhine river discharges, Water Resour. Res., 44, W01418, doi:10.1029/2007WR006168, 2008.

Jacob, D.: A note to the simulation of the annual and inter-annual variability of the water budget over the baltic sea drainage basin, Meteorol. Athos. Phys., 77, 61-73, 2001.

Jothityangkoon, M., Sivalapan, M., and Farmer, D. L.: Process controls of water balance variability in a large semi-arid catchment: Downward approach to hydrological model development, J. Hydrol., 254, 174-198, 2001.

Krause, P., Boyle, D. P. and Bäse, F.: Comparison of different efficiency criteria for hydrological model assessment, Adv. Geosci., 5, 89-97, 2005, http://www.adv-geosci.net/5/89/2005/.

Kundzewicz, Z. W., Mata, L. J., Arnell, N. W., Döll, P., Kabat, P., Jiménez, B., Miller, K. A., Oke, T., Sen, Z., and Shiklomanov, I. A.: Freshwater resources and their management, in: Climate change 2007: Impacts, adaptation and vulnerability, Contribution of working group ii tot the fourth assessment report of the intergovernmental panel on climate change, edited by: Parry, M. L., Conziani, O. F., Palutikof, J. P., Van der Linden, P. J., and Hanson, C. E., Cambridge University Press, Cambridge, UK, 173-210, 2007.

Kwadijk, J. C. J.: The impact of climate change on the discharge of the river Rhine, PhD Thesis, University of Utrecht, Utrecht, The Netherlands, 1993.

Liang, X., Lettenmaier, D. P., Wood, E. F., and Burges, S. J.: A simple hydrologically based model of land surface water and energy fluxes for general circulation models, J. Geophys. Res., 99, 415-428, 1994.

Liang, X., and Zhenghui, X.: A new surface runoff parameterization with subgrid-scale soil heterogeneity for land surface models, Adv Water Resour, 24, 1173-1193, 2001.

Lindström, G., Johansson, B., Persson, M., Gardelin, M., and Bergström, S.: Development and test of the distributed HBV-96 hydrological model, J. Hydrol., 201, 272-288, 1997.

Liu, Z. and Todini, E. Towards a comprehensive physically-bassed rainfall-runoff model. Hydrol. Earth Syst. Sci., 6, 859-881, 2002, http://www.hydrol-earth-syst-sci.net/6/859/2002/.

Lohmann, D., Nolte-Holube, R., and Raschke, E.: A largescale horizontal routing model to be coupled to land surface parametrization schemes, Tellus, 48A, 708-721, 1996.

Middelkoop, H., Daamen, K., Gellens, D., Grabs, W., Kwadijk, J. C. J., Lang, H., Parmet, B. W. A. H., Schädler, B., Schulla, J., and Wilke, K.: Impact of climate change on hydrological regimes and water resources management in the Rhine basin., Climatic Change, 49, 105-128, 2001.

Mitchell, T. D. and Jones, P. D.: An improved method of constructing a database of monthly climate observations and associated high-resolution grids, Int. J. Climatol., 25, 693-712, 2005.

Mülders, R., Parmet, B., and Wilke, K.: Hydrological modelling in the river Rhine basin. Final report, Federal Institute of Hydrology (BfG), KoblenzBfG - 125, 1999. 
Nash, J. E. and Sutcliffe, J. V.: River flow forecasting through conceptual models. Part i - a discussion of principles, J. Hydrol., 10, 282-290, 1970.

Passchier, R. and Stone, K.: Analysis of the instrumentation for computing design discharges, WL | Delft Hydraulics, Delft, The Netherlands, Q2705, 1-78, 2003.

Perrin, C., Michel, C., and Andréassian, V.: Does a large number of parameters enhance model performance? Comparative assessments of common catchment model structures on 429 catchments, J. Hydrol., 242, 275-301, 2000.

Pitman, A. J. and Perkins, S. E.: Reducing uncertainty in selecting climate models for hydrological impact assessments, in: Quantification and Reduction of Predictive Uncertainty for Sustainable Water Resource Management, Symposium HS2004 at IUGG2007, Perugia, 3-15, 2007.

Refsgaard, J. C.: Terminology, modelling protocol and classification of hydrological model codes, in: Distributed hydrological modelling, edited by: Abbott, M. B. and Refsgaard, J. C., Kluwer Academic Publishers, 17-39, 1996.

Reggiani, P., Hassanizadeh, S. M., Sivapalan, M., and Gray, W. G.: A unifying framework for watershed thermodynamics: Balance equations for mass, momentum, energy and entropy, and the second law of thermodynamics, Adv. Water Resour., 22, 367-398, 1998.

Reggiani, P., Hassanizadeh, S. M., Sivapalan, M., and Gray, W. G.: A unifying framework for watershed thermodynamics: Constitutive relationships, Adv. Water Resour., 23, 15-39, 1999.

Reggiani, P. and Schellekens, J.: Modelling of hydrological responses: The respresentative elementary watershed approach as an alternative blueprint for watershed modelling, Hydrol. Process., 17, 3785-3789, 2003.

Rientjes, T. and Zaadnoordijk, W. J.: Hoogwatervoorspelling: Fysisch gebaseerde regen-afvoermodellering. Dilemma of déjà vu?, Stromingen, 6, 33-44, 2000 (in Dutch).

Savenije, H. G.: Equifinality, a blessing in disguise?, Hydrol. Process., 15, 2835-2838, 2001.

Schär, C., Lüthi, D., Beyerly, U., and Heise, E.: The soilprecipitation feedback: A process study with a regional climate model, J. Climate, 12, 722-741, 1998.

Schulla, J. and Kaspar, K.: Model description WaSIM-ETH, Internal report, IAC, ETH, Zürich, 1-174, 2006.

Seibert, J.: Conceptual runoff models - fiction or representation of reality, MSc Thesis, Acta University, Uppsala, Sweden, 52 pp., 1999.

Shaw, E. M.: Hydrology in practice, Nelson Thornes Ltd, Cheltenham, England, 1-569, 2002.
Sprokkereef, E.: Eine hydrologische datenbank für das Rheingebiet, International Commission for the Hydrology of the Rhine Basin (CHR), 2001.

Te Linde, A. H.: Effect of climate change on the discharge of the rivers Rhine and Meuse. Applying the KNMI 2006 scenarios using the HBV model, WL | Delft Hydraulics, Delft, The Netherlands Q4286, 1-30, 2007.

Troy, T., Sheffield, J., and Wood, E.: Temporal and spatial scales in hydrological model calibration, in: Geophysical Research Abstracts, European Geosciences Union General Assembly 2007, Vienna, Austria, 2007,

Uhlenbrook, S., Seibert, J., Leibundgut, C., and Rodhe, A.: Prediction uncertainty of conceptual rainfall-runoff models caused by problems to identify model parameters and structure, Hydrol. Sci., 44, 779-798, 1999.

Uhlenbrook, S.: An emperical approach for delineating spatial units with the same dominating runoff generation processes, Phys. Chem. Earth, 28, 297-303, 2003.

Van Deursen, W. P. A. and Kwadijk, J. C. J.: Rhineflow: An integrated GIS water balance model for the river Rhine, HydroGIS 93: Application of Geographic Information Systems in Hydrology and Water Resources, 507-518, 1993.

Van Deursen, W. P. A.: Rapportage Rhineflow/Meuseflow. Nieuwe KNMI scenario's mei 2006,, Carthago Consultancy, Rotterdam, the Netherlands, 2006 (in Dutch).

Vivoni, E. R. Hydrologic modeling using triangulated irregular networks: terrain representation, flood forecasing and catchment response, PhD Thesis, Cambridge - Massaschusetts Institute of Technology, USA, 2003.

Wagener, T., McIntyre, N., Lees, M. J., Wheater, H. S., and Gupta, H. V.: Towards reduced uncertainty in conceptual rainfall-runoff modelling: Dynamic identifiability analysis, Hydrol. Process., 17, 455-476, 2003.

Ward, R. C. and Robinson, M.: Principles of hydrology, 4 ed., McGraw-Hill Publishing Company, London, 2000.

Weerts, A. H.: Assessing and quantifying the combined effect of model parameter and boundary uncertainties in model based flood forecasting., Geophys. Res. Abstr., 5, 14564, 2003.

Weerts, A. H. and Van der Klis, H.: FEWS-Rhine version 1.02. Improvements and adjustments., WL | Delft Hydraulics, Delft, Q3618, 2004.

Wessel, J.: Flood management of the transnational Rhine river. Proc. United States-Italy Research Workshop on Hydrometeorology, Impacts and Management of Extreme Floods, at Perugia, Italy, 13-17 November, 1995. 